\title{
POTENCIAL DO USO DO LODO DE ESGOTO COMO ADUBO ORGÂNICO EM COBERTURA DE ESPÉCIES FLORESTAIS NATIVAS PLANTADAS EM ÁREA DEGRADADA POR PASTAGEM
}

\section{POTENTIAL USE OF THE SEWAGE SLUDGE AS ORGANIC MANURING IN COVERING FORESTATION NATIVE ARBOREAL SPECIES PLANTED IN AREA DEGRADED BY INTENSIVE PASTURING}

\author{
Breno Viana Nascimento Silva, Tecnológo em Gestão Ambiental, brecorbi@gmail.com \\ Lilian Vilela Andrade Pinto, Professora do Instituto Federal de Educação, Ciência e Tecnologia do Sul de Minas \\ Gerais - Campus Inconfidentes, lilianvap@gmail.com.
}

\section{RESUMO}

O presente estudo teve como objetivo avaliar o efeito da aplicação do lodo de esgoto em cobertura no desenvolvimento silvicultural de nove espécies arbóreas nativas plantadas em área degradada por pastoreio intensivo. Para isso foram avaliados três tratamentos de adubação em cobertura: adubação orgânica com lodo de esgoto, adubação química com adubo (NPK 20-05-20) e testemunha (sem adubação). As espécies foram plantadas em dezembro de 2005 e as adubações em cobertura iniciouse em agosto de 2008. A resposta aos tratamentos foi avaliada pelo monitoramento dos parâmetros silviculturais diâmetro a altura do solo (DAS), altura (H) e diâmetro de Copa (DC) até março de 2009, totalizando cinco medições. O desenvolvimento do diâmetro a altura do solo apresentou diferença estatística entre os tratamentos com adubação de cobertura (NPK; lodo) e a testemunha apenas na espécie açoita cavalo (Luehea divaricata). Para as demais espécies, araucária (Araucaria angustifólia), cássia carnaval (Senna spectabilis), cedro (Cedrela fissilis), feijão cru (Lonchocarpus muehlbergianus), mochoqueiro (Erythrina falcata), peroba (Aspidosperma polyneuron), pimentinha 62 (Erythroxylum deciduum) e taiuveira (Maclura tinctoria) não foi verificado efeito das adubações nos parâmetros silviculturais avaliados. O lodo de esgoto não inibiu o desenvolvimento dos parâmetros silviculturais (DAS, H e DC) em nenhuma das espécies estudas. Assim, a utilização de lodo de esgoto como adubo orgânico pode ser utilizado como alternativa viável de fonte de matéria orgânica e nutriente, promovendo desenvolvimento satisfatório das espécies arbóreas e um menor gasto em adubações.

Palavras-chave: Espécies arbóreas, altura, diâmetro de copa, diâmetro a altura do solo.

\section{ABSTRACT}

The present study had as objective evaluates the effect of the application of the sewage sludge in covering in the development forestation of nine native arboreal species planted in area degraded by intensive pasturing. For that they were appraised three manuring treatments in covering: organic manuring with sewer mud, chemical manuring with fertilizer (NPK 20-05-20) and the witness (without manuring). The species were planted in december of 2005 and the manurings in covering, regarding this study, had beginning in august of 2008. The answer to the treatments was evaluated by the accompaniment of the parameters forestation diameter the height of the soil (DHS), height (H) and diameter of cup (DC) until march of 2009, totaling five measurements. The development of the diameter the height of the soil presented statistical difference among the treatments with covering manuring (NPK; mud) and the witness just in the specie Luehea divaricata. For the other species Araucaria angustifolia, 
Senna spectabilis, Cedrela fissilis, Lonchocarpus muehlbergianus, Erythrina falcata, Aspidosperma polyneuron, Erythroxylum deciduum and Maclura tinctoria effect of the manurings was not verified in the parameters appraised forestation. The sewage sludge didn't inhibit the development of the parameters forestation (DHS, H and DC) in none of the studied species. Like this, the use of sewage sludge as organic fertilizer can be used as viable alternative of source of organic and nutritious matter, promoting satisfactory development of the arboreal species and a smaller expense in manurings.

Word-key: Arboreal species, height, cup diameter, diameter the height of the soil.

\section{INTRODUÇÃO}

O lodo de esgoto ou biossólido é um resíduo rico em matéria orgânica e nutrientes que é gerado nas estações de tratamento de esgoto (ETEs) após o processo de estabilização, tornandose em seguida um empecilho nas ETEs.

maior parte desses resíduos são incinerados ou depositados em aterros sanitários, muitas vezes localizados a grandes distâncias das ETEs. Por isso torna-se importante estudos com o biossólido para que o mesmo não seja descartado de forma inadequada no ambiente, já que o transporte deste resíduo a grandes distâncias onera os custos de produção das indústrias.

Com intuito de atender a legislação atual que requer que o proprietário rural recupere suas áreas degradadas, a utilização de lodo de esgoto como adubo orgânico pode reduzir os custos de implantação, sendo uma grande opção para o produtor rural adotar em sua propriedade.

Estudos têm mostrado a eficiência do uso do lodo de esgoto no desenvolvimento de várias espécies e na eficiência do mesmo na melhoria das propriedades químicas e físicas do solo, uma vez que o biossólido atua como adubo fornecendo macro e micronutrientes ao solo, disponibilizandoos gradativamente através de mineralização (Tamanini et al., 2004), aumenta os teores de C orgânico no solo nas camadas de 5-10 e 10$20 \mathrm{~cm}$ de profundidade (Rocha et al., 2004), funciona como fertilizante para recuperação de áreas de mineração (Brofas et al., 2000; Tamanini et al., 2004; Bezerra et al., 2006), promove melhor agregação das partículas, melhorando sua estrutura e, com isso, o desenvolvimento radicular, a circulação de ar e água, incentivando um crescimento vegetal mais rápido, formando uma cobertura vegetal sobre o solo, protegendo-o (Ibáñez-Granell et al., 1993; Navas et al., 1999; Andreoli, 2001).

Entretanto, apesar dos efeitos benéficos, o lodo apresenta em sua composição, metais pesados (Bettiol \& Camargo, 2000) e microrganismos patógenos, que são prejudiciais a saúde animal e humana (Andreoli, 2001). Desta forma, a aplicação de lodo de esgoto em solos, principalmente sob culturas não destinadas à alimentação direta e sim para fins de reflorestamento, surge como uma alternativa promissora.

Assim, os objetivos deste estudo foram: i) avaliar a potencialidade do lodo de esgoto em cobertura em plantas já estabelecidas há dois anos e oito meses; ii) avaliar se a aplicação do lodo de esgoto inibe o desenvolvimento silvicultural das espécies arbóreas; e iii) comparar a adubação do lodo de esgoto com a adubação convencional (NPK - 20-05-20) e com a testemunha (não aplicação de adubação) no desenvolvimento silvicultural das espécies arbóreas.

\section{MATERIAS E MÉTODOS}

O experimento de adubação em cobertura foi realizado em uma área de pastagem degradada que já havia sido recuperada com espécies arbóreas nativas há 2 anos e 8 meses localizada na Fazenda do Instituto Federal de Educação, Ciência e Tecnologia do Sul de Minas Gerais - Campus Inconfidentes. Segundo a classificação climática de KOPEN o clima da região é do tipo Cwa, com característica de Cwb, 
apresentando precipitação média de $1744 \mathrm{~mm}$ e temperaturas médias anuais de $20^{\circ} \mathrm{C}$.

A instalação do experimento seguiu o delineamento estatístico inteiramente casualizado (DIC) em esquema fatorial $3 \times 9,3$ adubações em cobertura (i: Testemunha sem adubação; ii: Adubação em cobertura com 80 g de adubo 20-05-20; iii: Adubação orgânica em cobertura com $780 \mathrm{~g}$ de Lodo de Esgoto) e 9 espécies (Tabela 1), com 4 repetições.

TABELA 1. Espécies arbóreas nativas utilizadas para a recuperação da área de pastagem degradada seguidas de sua família, nome regional e grupo ecológico (GE): $\mathrm{P}=$ Pioneira e $\mathrm{C}=\mathrm{Climax}$.

\begin{tabular}{cccc}
\hline Espécie & Família & Nome regional & GE \\
\hline Aspidosperma polyneuron & Apocynaceae & Peroba & $\mathrm{C}$ \\
Cedrela fissilis & Meliaceae & Cedro & $\mathrm{C}$ \\
Erythrina falcata & Fabaceae Faboideae & Mochoqueiro & $\mathrm{P}$ \\
Erythroxylum deciduum & Erythroxylaceae & Pimentinha-62 & $\mathrm{P}$ \\
Lonchocarpus muehlbergianus & Fabaceae Faboideae & Feijão cru & $\mathrm{C}$ \\
Luehea divaricata & Malvaceae & Açoita-cavalo & $\mathrm{P}$ \\
Maclura tinctoria & Moraceae & Taiuveira & $\mathrm{P}$ \\
Araucaria angustifolia & Araucariáceas & Araucária & $\mathrm{C}$ \\
Senna spectabilis & Caesalpinioideae & Cássia-carnaval & $\mathrm{P}$ \\
\hline
\end{tabular}

Para estabelecer a quantidade de adubo orgânico (lodo de esgoto) a ser aplicado no experimento, por meio da recomendação de $80 \mathrm{~g}$ de adubo químico NPK (20-05-20), foi utilizado a equação 1 após a caracterização físico-química do lodo de esgoto originado da estação de tratamento de esgoto da indústria de bebida (Tabela 2).

Equação 1

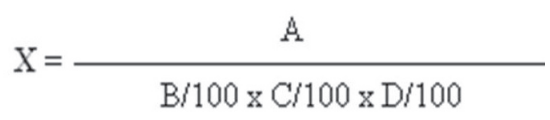

Onde: $\mathrm{X}=$ Quantidade de adubo a aplicar $(\mathrm{kg} /$ ha)
A $=$ Quantidade de nutriente aplicado
$\mathrm{B}=$ Matéria seca
$\mathrm{C}=$ Teor do nutriente na Matéria seca
$\mathrm{D}=$ Índice de conversão $(50 \%)$

TABELA 2. Caracterização físico-química do lodo de esgoto originado da estação de tratamento de esgoto da indústria de bebida.

\begin{tabular}{|c|c|c|}
\hline $\begin{array}{l}\text { Parâmetros } \\
\text { analisados }\end{array}$ & $\begin{array}{c}\text { Concentrações } \\
\text { médias }\end{array}$ & Desvio padrão \\
\hline $\mathrm{pH}$ & 6,17 & 0,110 \\
\hline Umidade (\%) & 11,972 & 0,794 \\
\hline $\mathrm{C}$ org. $\left(\mathrm{Mg} . \mathrm{Kg}^{-1}\right)$ & 164,761 & 3,557 \\
\hline M.O. $\left(\mathrm{Mg} \cdot \mathrm{Kg}^{-1}\right)$ & 298,703 & 12,030 \\
\hline Relação C:N & $3,5: 1$ & - \\
\hline N Kjeldahl (Mg.Kg $\left.{ }^{-1}\right)$ & 46,698 & 5,296 \\
\hline$P$ total $\left(\mathrm{mg} . \mathrm{l}^{-1}\right)$ & 4132,917 & 866,734 \\
\hline $\mathrm{K}\left(\mathrm{Mg} \cdot \mathrm{Kg}^{-1}\right)$ & 3,637 & 0,733 \\
\hline $\mathrm{ST}\left(\mathrm{Mg} \cdot \mathrm{Kg}^{-1}\right)$ & 880,282 & 7,487 \\
\hline $\mathrm{SF}\left(\mathrm{Mg} \cdot \mathrm{Kg}^{-1}\right)$ & 111,374 & 15,513 \\
\hline $\mathrm{SV}\left(\mathrm{Mg} \cdot \mathrm{Kg}^{-1}\right)$ & 776,976 & 8,336 \\
\hline
\end{tabular}

O lodo de esgoto foi triturado em picadeira movida por um trator para facilitar a sua aplicação em cobertura.

As avaliações do desempenho das espécies no campo foram por meio dos parâmetros altura (H), diâmetro à altura do solo (DAS) e diâmetro de 
copa (DC) em plantas já desenvolvidas, plantadas em dezembro de 2005.

As avaliações tiveram inicio no mês de agosto de 2008, quando as plantas já tinham 2 anos e 8 meses de plantio, e término em março de 2009, quando as plantas tinham 3 anos e 3 meses de plantio, totalizando 5 avaliações.

Os dados dos parâmetros avaliados foram submetidos à análise de variância (ANAVA) e as médias foram comparadas pelo teste de Skott-Knott, a $5 \%$ de probabilidade, usando-se o programa SISVAR 4.3. Os gráficos foram gerados a partir do programa Sigma Plot2000 e Excel.

\section{RESULTADOS E DISCUSSÃO}

A variável altura $(\mathrm{H})$ não teve seu desenvolvimento afetado de forma significativa ao nível $5 \%$ de probabilidade pelo teste de médias de Scott-knott entre os tipos de adubação de cobertura e a testemunha (Figura 1). As espécies que apresentaram melhores respostas à adubação de cobertura com adubo químico (20-05-20) foram açoita cavalo (Luehea divaricata), cedro (Cedrela fissilis) e peroba (Aspidosperma Polyneuron), e as espécies que melhor responderam à adubação de cobertura com lodo de esgoto foram araucária (Araucaria angustifólia), mochoqueiro (Erythrina falcata) e taiuveira (Maclura tinctoria). As espécies, cássia carnaval (Senna spectabilis), feijão cru (Lonchocarpus Muehlbergianus) e Pimentinha 62 (Erythroxylum deciduum) tiveram maior tendência de crescimento no tratamento testemunha.

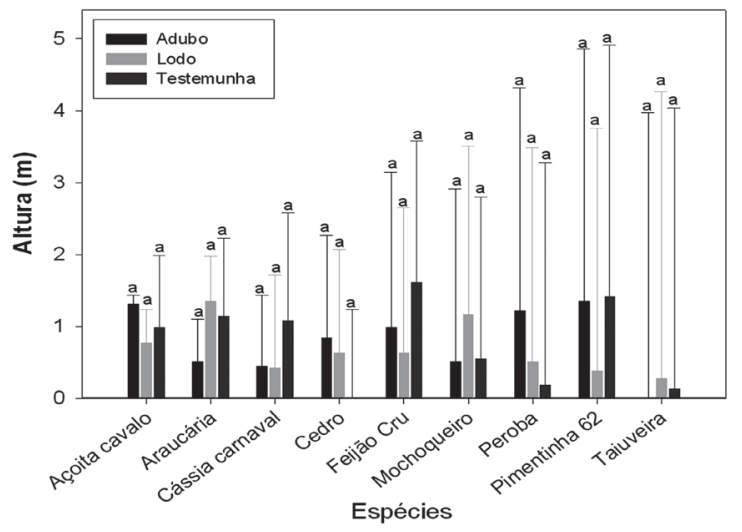

FIGURA 1 - Diferença do crescimento em altura em cinco avaliações de nove espécies nativas em Inconfidentes - MG, sob diferentes adubações em cobertura.

O desenvolvimento do diâmetro a altura do solo (DAS) apresentou diferença estatística entre os tratamentos com adubação de cobertura (NPK; lodo) e a testemunha apenas na espécie açoita cavalo (Luehea divaricata) (Figura 2). Para as demais espécies não verificou-se efeito das adubações no desenvolvimento do diâmetro a altura do solo quando comparado com a testemunha. As espécies que apresentaram melhores respostas à adubação de cobertura com adubo químico (20-05-20) foram araucária (Araucaria angustifólia), cedro (Cedrela fissilis), peroba (Aspidosperma polyneuron) e taiuveira (Maclura tinctoria). Já as espécies que melhor responderam à adubação de cobertura com lodo de esgoto foram mochoqueiro (Erythrina falcata), feijão cru (Lonchocarpus muehlbergianus) e pimentinha 62 (Erythroxylum deciduum), assim como em estudo realizado por Caldeira Júnior et al. (2007), os quais verificaram que o diâmetro do caule da aroeira apresentou resposta quanto à adição de lodo de esgoto ao solo, tendo seu desenvolvimento máximo. A espécie cássia carnaval (Senna spectabilis) teve tendência de maior desenvolvimento quando não foi adubada (tratamento testemunha).

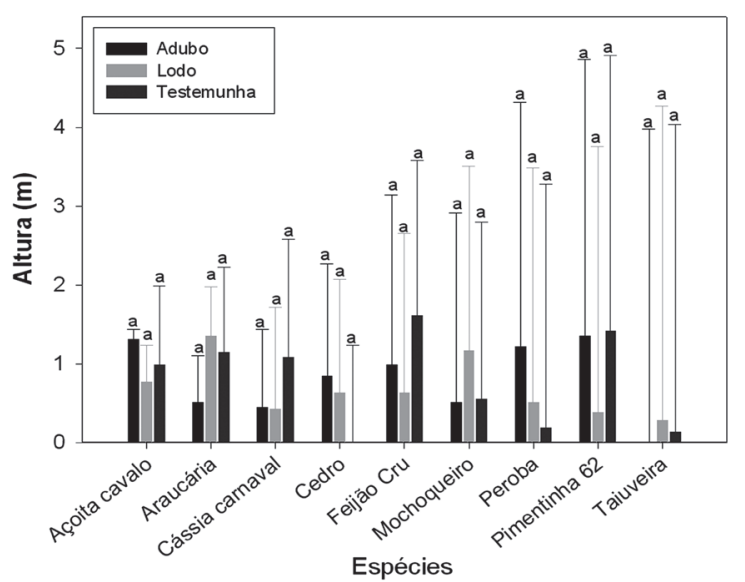


FIGURA 2 - Diferença do crescimento em diâmetro a altura do solo em cinco avaliações de nove espécies nativas em Inconfidentes - MG, sob diferentes adubações em cobertura.

O desenvolvimento do diâmetro de copa (DC) não apresentou diferença estatística entre os tratamentos com adubação de cobertura (NPK; lodo) e a testemunha (Figura 3). As espécies que desenvolveram melhor na adubação de cobertura com adubo químico (NPK 20-0520) foram às espécies açoita cavalo (Luehea divaricata), cássia carnaval (Senna spectabilis), peroba (Aspidosperma polyneuron) e taiuveira (Maclura tinctoria). Já a araucária (Araucaria angustifólia), feijão cru (Lonchocarpus Muehlbergianus), mochoqueiro (Erythrina falcata) e Pimentinha 62 (Erythroxylum deciduum) tiveram maior crescimento na adubação de cobertura com lodo de esgoto, assim como em estudos realizados por Caldeira Júnior et al. (2007), onde a projeção de copa da aroeira foi aumentada conforme a adição de lodo de esgoto. A espécie que desenvolveu melhor no tratamento sem adubação (testemunha) foi o cedro (Cedrela fissilis), a qual não apresentou diferença estatística em comparação com os tratamentos que receberam adubações.

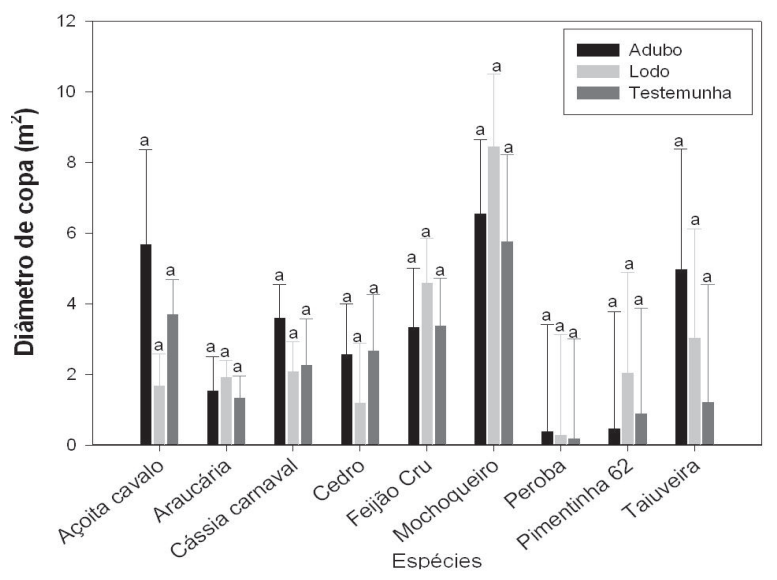

FIGURA 3 - Diferença do crescimento em diâmetro de copa em cinco avaliações de nove espécies nativas em Inconfidentes - MG, sob diferentes adubações em cobertura.
Em todos os parâmetros avaliados o lodo de esgoto mostrou-se potencializador do desenvolvimento das espécies estudadas. Estas respostas podem ser devidas, segundo Tamanini et al (2004), o biossólido atuar como adubo orgânico fornecendo macro e micronutrientes ao solo, disponibilizando-os gradativamente através de mineralização, e com isso, resultar em um maior desenvolvimento da vegetação. Rocha et al. (2004) avaliando os efeitos de doses crescentes de lodo de esgoto na fertilidade de um Latossolo Vermelho Amarelo distrófico, na cultura do eucalipto, observou que, aos 32 meses após aplicação do lodo, houve aumento nos teores de $\mathrm{C}$ orgânico com o acréscimo das doses de lodo usadas, em comparação com o tratamento testemunha e o que recebeu apenas adubação mineral, sendo esse maior acúmulo verificado nas camadas de solo de 5-10 e 10-20 cm.

Dentre os três parâmetros silviculturais avaliados (altura, diâmetro a altura do solo e diâmetro de copa) o lodo de esgoto teve melhor resposta no parâmetro diâmetro a altura do solo com diferença de $6,1 \%$ quando comparado com adubo NPK e de $24,5 \%$ quando comparado a testemunha (Figura 4). Amelhor resposta do lodo de esgoto neste parâmetro é muito importante por realmente mostrar o ganho de crescimento da espécie uma vez que o valor mensurado neste parâmetro independe se houve queda de folhas, o que afeta os valores mensurados na altura e no diâmetro de copa. Deve-se ressaltar ainda que o lodo de esgoto proporcionou maior desenvolvimento nas variáveis altura e diâmetro de copa quando comparado com a testemunha, com valores percentuais superiores a testemunha de $5,1 \%$ e $8,9 \%$, respectivamente (Figura 4 ). 


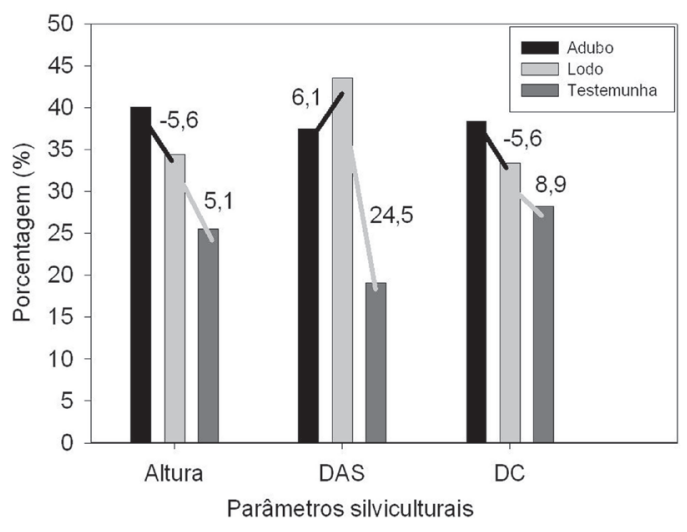

FIGURA 4 - Diferença em porcentagem entre o lodo e os tratamentos: NPK e testemunha

O lodo de esgoto tem sido utilizado, largamente, como condicionador e fertilizante para recuperação de áreas de mineração (Brofas et al., 2000). Ibáñez-Granell et al. (1993) e Navas et al. (1999) ressaltam o efeito positivo da aplicação do lodo, no desenvolvimento da vegetação e na recuperação de solos degradados e ácidos, pois a incorporação de matéria orgânica restabelece a estrutura, melhora a circulação de ar e água e libera nutrientes essenciais ao desenvolvimento da vegetação. Conforme Andreoli et al. (2001) a aplicação de lodo de esgoto ao solo promove melhor agregação das partículas, melhorando sua estrutura e, com isso, o desenvolvimento radicular e a infiltração de água, incentivando um crescimento vegetal mais rápido, formando uma cobertura vegetal sobre o solo, protegendo-o.

Assim, seguindo-se à risca as recomendações de adubação, a utilização de lodo de esgoto como adubo nitrogenado é uma alternativa viável para os produtores que queiram recuperar suas áreas degradadas, de modo a diminuírem seus gastos e aumentarem sua produtividade em um espaço curto de tempo, e também, ao meio ambiente, por aliviar a carga de esgotos nos mananciais de água.

\section{CONCLUSÕES}

A adubação em cobertura com lodo de esgoto não inibiu o crescimento dos parâmetros silviculturais altura, diâmetro a altura do solo e diâmetro de copa nas noves espécies arbóreas estudadas.

O desenvolvimento silvicultural das plantas adubadas com lodo de esgoto foi superior aos das plantas que não receberam adubação.

O desenvolvimento do diâmetro a altura do solo (DAS) apresentou diferença estatística entre os tratamentos com adubação de cobertura (NPK; lodo) e a testemunha apenas na espécie açoita cavalo (Luehea divaricata).

O lodo de esgoto é uma alternativa viável ao meio ambiente podendo ser utilizado na recuperação de áreas degradadas por pastagens, diminuindo gastos e aumentando a produtividade da vegetação estabelecida no local.

\section{REFERÊNCIAS BIBLIOGRÁFICAS}

ANDREOLI, C. V. Uso e manejo do lodo de esgoto na agricultura e sua influência em características ambientais no agrossistema. 1999. 278p. Tese de Doutorado - Universidade Federal do Paraná.

ANDREOLI, C.V.; SPERLING, M.Von; FERNANDES, F. Lodos de esgoto: tratamentoe disposição final. Belo Horizonte: Departamento de Engenharia Sanitária e Ambiental - UFMG; Companhia de Saneamento do Paraná; v.6, 484p. 2001.

BETTIOL, W.; CAMARGO, O.A. Agricultura: opção animadora para a utilização de lodo de esgoto. O Agronômico, Campinas, v. 52, n. 2/3, p. 13-16. 2000.

BEZERRA, F. B.; OLIVEIRA, M. A. C. L.; PEREZ, D. V.; ANDRADE, A. G.; MENEGUELLI, N. A. Lodo de esgoto em revegetação de área degradada. Revista Pesquisa Agropecuária Brasileira, Brasília, 
v.41, n.3, p.469-476, mar. 2006

BROFAS, G.; MICHOPOULOS, P.; ALIFRAGIS, D. Sewage sludge as an amendment for calcareous bauxite mine spoils reclamation. Journal of Environment Quality, v.29, p.811- 816, 2000.

CALDEIRA JÚNIOR, C.F., SOUZA, R.A., MARTINS, E.R., SAMPAIO, R.A. Crescimento de aroeira sob adubação com lodo de esgoto e silicato visando a revegetação de área degradada. Revista Brasileira de Biociências, Porto Alegre, v. 5, supl. 1, p. 261-263, jul. 2007.

IBÁÑEZ-GRANELL， A.; SANCHÍS， A.; GARCÍA CAMARERO, J.; INGELMOSÁNCHEZ, F. Reclamation of abandoned land with sewage sludge and plant cover. Studia
Oecológica, v.10, p.101-108, 1993.

NAVAS, A.; MACHÍN, J.; NAVAS, B. Use of biossolids to restore the natural vegetation cover on degraded soils in the badlands of Zaragoza (NE Spain). Bioresource Technology, v.69, p.199205, 1999.

ROCHA, G.N.; GONÇALVES, J.L.M.; MOURA, I.M. Mudanças da fertilidade do solo e crescimento de um povoamento de Eucalyptus grandis fertilizado com biossólido. Revista Brasileira de Ciência do Solo, v.28, p.623-639, 2004.

TAMANINI, C.R., ANDREOLI, C.V., MOTTA, A.C.V., DOETZER, B.H., PEGORINI, E.S. Estudo da utilização de altas doses de biossolido na recuperação de área decapada em São José dos Pinhais. In: $\mathbf{2 3}^{\circ}$ Congresso Brasileiro de Engenharia Sanitária e Ambiental. 2004. 16p. 